\title{
A NEW MEASURE OF VISUAL DISCRIMINATION`
}

\section{BY KNIGHT DUNLAP}

The tests on which this report is based were carried out in the Nela Research Laboratory in August and September of 1914, as an adjunct to other experimental work which will be reported later. The instrument used was constructed at The Johns Hopkins University several years ago, and as a result of work with it since that time has been modified into the present form, which seems good in principle although the mechanical operation may still be improved.

The instrument which, for convenience, may be called a duoscope, consists essentially of a polished crystal of Iceland spar mounted in a telescopic brass tube, which has an eyeaperture at one end, and a rotatable ring at the other. The ring is rotated by a worm-screw with a knurled head, and is provided with a vernier scale, so that the angle of rotation may be read to one fifth of a degree. The ring is arranged to hold a disc fitting within it, so that various forms of objects may be viewed at a fixed distance from the eye.

The first objects tried were as near linear as possible: a diamond-scratch on a clear glass disc; a fine glass filament crossing a circular aperture in a metal disc. These were tried against various backgrounds, and were not satisfactory because of the difficulty of securing a line of sufficient uniformity and without sheen. A narrow slit was equally unsatisfactory. Finally a rectangular aperture of appreciable width was found workable when used against a bright background.

The Iceland spar crystal gives a double image of the line (or rectangle) used as an object, and the relation of these two images may be altered by rotating the ring which carries the line with it. If the line stands exactly in the refracting

1 From the Nela Research Labotatory, National Lamp Works of the General Electric Company. 
plane of the crystal, the two images are superposed over their greater length, their displacement being longitudinal only. If the line be rotated $90^{\circ}$ from this position, the two images are displaced laterally to the maximal distance possible from the prism ( $1.089 \mathrm{~mm}$. with the crystal used in the present work), and if this distance be greater than the width of the line (or rectangle) the two images are separated.

In this way, with a proper linear object, it would be easily possible to measure (in terms of the visual angle) the displacement of the images giving just perceptible doubleness; $i$. e., the minimum visibile. The advantage of the device lies in the exactness of measurement and ease of manipulation, with the possibility of accommodation for relatively short or ' $\mathrm{read}$ ing distance.' It is possible to obtain a suitable linear object, but before I had found one I discovered that observation on a rectangle of appreciable width (i.e., a relatively wide slit) is much easier, and have therefore adopted such an object for the present. The fineness of measurement possible with this instrument is indicated by the fact that the reading unit in the vernier scale (one fifth of a degree) corresponds, in the middle of the scale used in the present work, to $1.6^{\prime \prime}$ of visual angle, or $.0029 \mathrm{~mm}$. lateral displacement of the image.

The discrimination of doubleness in lines is of course a matter primarily of difference-sensibility for brightness. If (in the case of two bright lines, or two images of a single objective bright line), there is a perceptible dark stripe down the middle of the combined lines, they are seen as two; if there is no dark stripe, as one. The three factors involved in 'visual acuity' as tested by the linear method ${ }^{1}$ are therefore: (I) The physical distribution of the light-flux on the retina, determined by the 'resolving power' of the eye; (2) The distribution of energy or activity in the physiological image of the retina, determined by the distribution, in the physical image, and by irradiation, etc.; (3) The difference-sensibility for brightness differences. Anything which changes any of these factors, as a change in the lens system, or in the irradi-

1 In the case of determinations by means of two points instead of two lines, the situation is different, and the histological texture of the retina may be a factor. 
ation, will therefore change the 'acuity,' although the difference-sensibility remains the same. Thus the practical usefulness of the acuity-determination depends on thorough (and perhaps unattainable) control of the conditions of observation. These matters are so obvious that no further discussion is needed here.

The method of testing 'acuity' by the double images of a bright rectangle is now apparent. If the two images (physical) overlap sufficiently, there is a brighter line in the middle of the combined images; if they are sufficiently separated there is a darker line in the middle. It is a relatively simple matter to determine the points at which the dark line and the bright line are $j u s t$ perceptible.

The crystal used has a maximal image-separation of $1.089 \mathrm{~mm}$., and the slit was fixed at a distance of approximately $36 \mathrm{~cm}$. from the eye. The slit was $3 \mathrm{~cm}$. long and $0.77 \mathrm{~mm}$. wide.

The most difficult part of the adjustment of the instrument is the determining of the position in which there is no lateral, but only longitudinal, displacement of the images. This determination was made by long series of observations of the bright line obtained by moving in each direction alternately, determining the middle point from these. The zero point thus obtained is sufficiently exact for practical purposes; besides, no more exact method is available.

The background against which the slit was viewed was a plane disc of plaster surfaced with magnesia, at a distance of $97 \mathrm{cms}$. from the rectangle. ${ }^{1}$ This was used first in a darkened room and illuminated with a beam of light from a nitrogen tungsten lamp. The lamp being enclosed, the only illumination of the room was the light diffused from the disc. From the direct radiation of this light the observer was protected by a black screen, through which the instrument protruded. The observer was therefore not in complete darkness, but the illumination in his direction was low (1/27 to 2 c.p.). Ten minutes or more was allowed for adaptation, so that the subject was really in a fair state of darkness adaptation.

1 Tests were made at other distances, but as was expected, the distance proved not to be a factor in the results. 
Subsequently the instrument and plaster disc were moved into a room well lighted with daylight, so that measurements were obtained with daylight adaptation.

In the darkened room five illuminations of the plaster background were used, giving brightnesses of 3, 10, 36, 82 and 168 candles per square meter.

The observers were: laboratory helper Mr. Eric Martienssen, a high school graduate; Dr. P. W. Cobb; Dr. H. M. Johnson; and myself. The readings on me were taken by Martienssen; the readings on the other observers were taken by me. Usually twenty-five determinations were made in one sitting. Thus, in the work with five intensities, five determinations were made on each intensity at a sitting, with only one sitting a day. Each subject had preliminary practice in observing. These intensities were taken in a different order on different days. No practice effect is noticeable in the measurements of any of the subjects.

The observer started with the bright line plainly visible and rotated the slit until the dark line was just visible: then he rotated the slit in the other direction until the bright line was just visible: or vice versa. The observers found it easier to make the changes rather quickly. Long looking caused the difference in brightness to disappear.

It is unfortunate that the instrument was made with the crystal fixed, and the object rotating. It was so made because this form allows easier construction, and has advantages in adjustment of the object for the zero point which was desirable while the instrument was in the provisional stage. The next instrument will be made with fixed object-holder, so that the axis of the slit will not change during observations.

The rotation of the axis in these experiments was small, however, and does not vitiate the results. In the table below, where the axis is not specified, it was $90^{\circ}$, that is the slit was vertical when in the medial position, i. e., in the position in which the images were not displaced laterally.

The readings given in the table are the displacements from the zero position in visual angle computed from the averages of the designated number of readings on the scale 
of the instrument. Theoretically, the visual angle should have been computed for each instrument-reading, and then the averages of the computed values taken; practically, the computation for the average of the instrument-readings is sufficiently accurate. The mean variations are not given, because I have so far not been able to discover what the true mean variations are. It is evident that the variations cannot be referred to the averages, because these vary with the width of the slit employed, regardless of the uniformity of observations; nor to the average of the range from dark line to bright line, because there may be variations in the readings which do not affect this.

\section{TABLE I}

The Influence of Brightness and of Adaptation
1. Martienssen. Left Eye
2. Johnson. Right Eye

A. Dark Adaptation. Av. of 25

A. Dark Adaptation. Av. of 25

\begin{tabular}{|c|c|c|c|c|c|c|}
\hline Brightness & Dk. Lune & Br. Line & Range & Dk. Line & Br. Iine & Range \\
\hline $\begin{array}{r}3 \\
10 \\
36 \\
82 \\
168 \\
\end{array}$ & $\begin{array}{l}7^{\prime} 10^{\prime \prime} \\
7^{\prime} 10^{\prime \prime} \\
7^{\prime}, 10^{\prime \prime} \\
7^{\prime}, 10^{\prime \prime} \\
7^{\prime} 0^{\prime \prime}\end{array}$ & $\begin{array}{l}6^{\prime} 44^{\prime \prime} \\
6^{\prime} 49^{\prime \prime} \\
6^{\prime} 50^{\prime \prime} \\
6^{\prime} 53^{\prime \prime} \\
6^{\prime} 54^{\prime \prime}\end{array}$ & $\begin{array}{l}26^{\prime \prime} \\
21^{\prime \prime} \\
20^{\prime \prime} \\
17^{\prime \prime} \\
13^{\prime \prime}\end{array}$ & $\begin{array}{l}6^{\prime} 59^{\prime \prime} \\
7^{\prime} 1^{\prime \prime} \\
6^{\prime} \quad 59^{\prime \prime} \\
7^{\prime}, 0^{\prime \prime} \\
7^{\prime} \quad 2^{\prime \prime}\end{array}$ & $\begin{array}{l}6^{\prime} 46^{\prime \prime} \\
6^{\prime} 49^{\prime \prime} \\
6^{\prime} 49^{\prime \prime} \\
6^{\prime} 49^{\prime \prime} \\
6^{\prime} 50^{\prime \prime}\end{array}$ & $\begin{array}{l}13 " \\
12^{\prime \prime} \\
10^{\prime \prime} \\
1 \mathbf{I}^{\prime \prime} \\
1 \mathbf{I}^{\prime \prime}\end{array}$ \\
\hline
\end{tabular}

B. Daylight Adap. Av. of 20

B. Daylight Adap. Av. of 20

\begin{tabular}{l|l|l|l|l|l|l|l}
\hline $7^{\prime} 2^{\prime \prime}$ & $6^{\prime} 5^{\prime \prime}$ & $\mathrm{II}^{\prime \prime}$ & $6^{\prime} 59^{\prime \prime}$ & $6^{\prime} 47^{\prime \prime}$ & $\mathrm{I2}^{\prime}$ \\
\hline
\end{tabular}

3. Cobb. Right Eye

A. Dark Adap. Av. of to
4. Durlap. Lefi Eye

A. Dark Adap. Av, of 25

\begin{tabular}{r|l|l|l|l|l|l}
3 & $6^{\prime} 50^{\prime \prime}$ & $6^{\prime} 27^{\prime \prime}$ & $23^{\prime \prime}$ & $7^{\prime} 10^{\prime \prime}$ & $6^{\prime} 39^{\prime \prime}$ & $31^{\prime \prime}$ \\
10 & $6^{\prime} 53^{\prime \prime}$ & $6^{\prime} 31^{\prime \prime}$ & $22^{\prime \prime}$ & $7^{\prime} 11^{\prime \prime}$ & $6^{\prime} 48^{\prime \prime}$ & $23^{\prime \prime}$ \\
36 & $6^{\prime} 49^{\prime \prime}$ & $6^{\prime} 26^{\prime \prime}$ & $23^{\prime \prime}$ & $7^{\prime} 11^{\prime \prime}$ & $6^{\prime} 49^{\prime \prime}$ & $22^{\prime \prime}$ \\
82 & $6^{\prime} 51^{\prime \prime}$ & $6^{\prime} 34^{\prime \prime}$ & $17^{\prime \prime}$ & $7^{\prime} 11^{\prime \prime}$ & $6^{\prime} 50^{\prime \prime}$ & $21^{\prime \prime}$ \\
168 & $6^{\prime} 52^{\prime \prime}$ & $6^{\prime} 33^{\prime \prime}$ & $19^{\prime \prime}$ & $7^{\prime} 12^{\prime \prime}$ & $6^{\prime} 50^{\prime \prime}$ & $22^{\prime \prime}$ \\
\hline
\end{tabular}

$B$. Daylight Adap. Av. of 75

\begin{tabular}{l|l|l|l|l|l}
\hline 1 & & $7^{\prime} 4^{\prime \prime}$ & $6^{\prime} 49^{\prime \prime}$ & $15^{\prime \prime}$ \\
\hline
\end{tabular}

In the $A$ parts of Table I are given the general results of the tests with different brightness of slit under darkness adaptation, and in the $B$ parts, the corresponding results with daylight adaptation. Two points are clear. First, that in general the daylight adaptation gives greater acuity; and 


\section{TABLE II}

Inrlugnce of Angle of Axis of Rectangle

I. Dunlap. Right Eye

A. Daylight Adap. With lens correction. Av.of 20

\begin{tabular}{|c|c|c|c|c|c|c|}
\hline Axis & Dk. Liue & Br. Lane & Range & Dk. Line & Br. Line & Range \\
\hline $\begin{array}{r}80 \\
90 \\
100 \\
125 \\
170\end{array}$ & $\begin{array}{ll}7^{\prime} & 2^{\prime \prime} \\
7^{\prime} & 2^{\prime \prime} \\
7^{\prime} & 2^{\prime \prime} \\
7^{\prime} & 2^{\prime \prime} \\
7^{\prime} & 6^{\prime \prime}\end{array}$ & $\begin{array}{l}6^{\prime} 46^{\prime \prime} \\
6^{\prime} 45^{\prime \prime} \\
6^{\prime} 42^{\prime \prime} \\
6^{\prime} 42^{\prime \prime} \\
6^{\prime} \quad 50^{\prime \prime}\end{array}$ & $\begin{array}{l}16^{\prime \prime} \\
17^{\prime \prime} \\
20^{\prime \prime} \\
20^{\prime \prime} \\
16^{\prime \prime}\end{array}$ & & & \\
\hline
\end{tabular}

$B$. Daylight Adap. Without lens

Av. of 10
C. Dark Adap. Without lens

Av, of 40

\begin{tabular}{|c|c|c|c|c|c|c|}
\hline $\begin{array}{r}80 \\
125 \\
170\end{array}$ & $\begin{array}{ll}7^{\prime} & 4^{\prime \prime} \\
7^{\prime} & 10^{\prime \prime} \\
7^{\prime} & 9^{\prime \prime}\end{array}$ & $\begin{array}{l}6^{\prime} 43^{\prime \prime} \\
6^{\prime}, 32^{\prime \prime} \\
6^{\prime} 55^{\prime \prime}\end{array}$ & $\begin{array}{l}21^{\prime \prime} \\
38^{\prime \prime} \\
14^{\prime \prime}\end{array}$ & 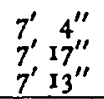 & $\begin{array}{l}6^{\prime} 40^{\prime \prime} \\
6^{\prime} 22^{\prime \prime} \\
6^{\prime} 46^{\prime \prime}\end{array}$ & $\begin{array}{l}24^{\prime \prime} \\
55^{\prime \prime} \\
27^{\prime \prime}\end{array}$ \\
\hline
\end{tabular}

2. Martienssen. Daylight Adap. Av. of 20

A. Right Eye

$B$. Left Eye

\begin{tabular}{c|c|c|c|c|c|c|c}
90 & $7^{\prime} 9^{\prime \prime}$ & $6^{\prime} 53^{\prime \prime}$ & $16^{\prime \prime}$ & $7^{\prime} 2^{\prime \prime}$ & $6^{\prime} 51^{\prime \prime}$ & $11^{\prime \prime}$ \\
135 & $7^{\prime \prime} 0^{\prime \prime}$ & $6^{\prime} 4^{\prime \prime}$ & $12^{\prime \prime}$ & $7^{\prime}$ & $8^{\prime \prime}$ & $6^{\prime} 54^{\prime \prime}$ & $14^{\prime \prime}$ \\
180 & Unable to & see lines. & & $7^{\prime}$ & & $7^{\prime}$ \\
67.5 & Unable to & see lines. & & $7^{\prime \prime}$ & $22^{\prime \prime}$ & $21^{\prime \prime}$ \\
\hline
\end{tabular}

3. Johnson. Daylight Adap. Ao. of ro

A. Right Eye

B. Left Eye

\begin{tabular}{|c|c|c|c|c|c|c|}
\hline $\begin{array}{c}90 \\
135 \\
189 \\
67.5\end{array}$ & $\begin{array}{c}\left(6^{\prime}, 59^{\prime \prime}\right) \\
6^{\prime}, 55^{\prime \prime} \\
7^{\prime}, \infty^{\prime \prime} \\
7^{\prime} \infty^{\prime \prime}\end{array}$ & $\begin{array}{c}\left(6^{\prime}, 47^{\prime \prime}\right) \\
6^{\prime}, 46^{\prime \prime} \\
6^{\prime}, 4^{\prime \prime \prime} \\
6^{\prime} 4^{\prime \prime \prime}\end{array}$ & $\begin{array}{c}\left(12^{\prime \prime}\right) \\
9^{\prime \prime} \\
12^{\prime \prime} \\
12^{\prime \prime}\end{array}$ & $\begin{array}{l}6^{\prime}, 59^{\prime \prime} \\
6^{\prime}, 59^{\prime \prime} \\
6^{\prime}, 58^{\prime \prime} \\
6^{\prime} 59^{\prime \prime}\end{array}$ & $\begin{array}{l}6^{\prime} 45^{\prime \prime} \\
6^{\prime}, 47^{\prime \prime} \\
6^{\prime}, 45^{\prime \prime} \\
6^{\prime} 46^{\prime \prime}\end{array}$ & $\begin{array}{l}14^{\prime \prime} \\
12^{\prime \prime \prime} \\
13^{\prime \prime \prime} \\
14^{\prime \prime}\end{array}$ \\
\hline
\end{tabular}

second, that there is no uniform influence of brightness within the limits of the conditions obtaining.

The results with the lowest brightness differ appreciably from the results with the higher brightness, but this is due, in part at least, to the difficulty in judging with this illumination when near the line-threshold. This is a condition which must be distinguished carefully from the raising of the threshold as such, and was clearly a factor in my own case. Leaving out the dimmest light, the influence of the brightness is negligible for Cobb, Johnson, and Dunlap.

The change to daylight adaptation is, however, influential except in the case of Johnson, whose acuity seems to be 
exceptional. Tests with the Cobb acuity-object also have shown Johnson to have unusual acuity with darkness adaptation. It is quite probable that the slight effect of the increasing illumination in the darkened room was due to the lessening of adaptation.

The most striking result is the uniform lowness of the threshold. The average range from dark line to bright line lies for the most part near 20", and is lower in some cases. In the ordinary test object, using object lines, the measurement from fusion to dark line is from $30^{\prime \prime}$ to $60^{\prime \prime}$. The corresponding measurement in the present case is less than $20^{\prime \prime}$; how much less cannot be determined, as it cannot be assumed that either the points of geometrical contiguity, or of physical uniformity of the images, lie half way between the points at which the dark line and the bright line respectively appear. Schuster states that the intensity at the edge of the geometrical image of a uniformly bright surface must be "half the intensity observed at some distance inside the edge," because when two surfaces are placed with edges in contact a uniformly illuminated surface is obtained. ${ }^{1}$ Assuming this to be true of the physical image, it is not necessarily true of the psychological image, as irradiation and contrast (physiological) effects occur at the margins of the images. The fact that both light line and dark line thresholds tend to shift with darkness adaptation indicates influences of this sort, and we should accordingly expect the light line threshold in general to be nearer the point of geometric image contiguity than is the dark line threshold: an expectation that is justified by the facts.

Table II gives the results of tests to find the effects of lenticular aberrations. My right eye is corrected with a lens of $0.5^{\circ} \mathrm{C}$., axis $80^{\circ}$, prism $3 / 4^{\circ}$ B.D. Tests were accordingly made on the eye with and without the correcting lens, in the astigmatic axis and at $45^{\circ}$ on either side. The results (II, I, $A, B$, and $C$ ) show that even a low degree of astigmatism is detectible by this means and also that my eye is slightly undercorrected by the lens.

' Schuster, 'Theory of Optics,' page 151. 
Tests were carried out on both of Martienssen's eyes (II, 2). He preferred to use his left eye in any sort of monocular observation. On being questioned about this he said he had always used that eye because it seemed more natural. The tests seem to indicate a slight degree of astigmatism in the right eye with less in the left. Martienssen's eyes had never been refracted. ${ }^{2}$ The degree of astigmatism is not great, for with uncorrected eyes requiring from one to two diopters of cylindrical correction, the instrument cannot be used at all.

Whether the instruments and methods for acuity test above described will be practically useful remains to be seen. In the matter of precision and convenience the apparatus seems superior to devices hitherto in use. The fact that the results differ from those obtained by means of the several other devices is immaterial. Measurements of this kind give comparable results only when the same instruments and methods are used. Since the duoscope method seems sensitive to adaptation changes, it may be possible to use it as an adaptometer; since it seems not sensitive to brightness changes over a considerable range, it may be a useful instrument for practical testing of eyes. It seems especially suitable for detecting slight degrees of astigmatism, and for detecting the accuracy with which lens corrections for astigmatism are made, in experimental work where accurate control of the observer's eye is required.

${ }^{1}$ Since the above was written, Dr. Cobb has refracted Martienssen's eyes, with the following results (sine midriatic):

$$
\begin{aligned}
& \text { O.D. }-\quad 37 \text { cyl. axis } 175^{\circ} \\
& \text { O.S. }-. \quad 25 \text { sph. }-\quad 37 \text { cyl. axis } 155^{\circ} \text {. }
\end{aligned}
$$

It is probable that the fact that the duoscope readings for the Right Eye are not barmonious (e. g., the inefficiency at 67.5), is due to over accomodation. 